ponent of a COPD self-management program in a recent multi-centre RCT.

Methods: Patients were randomly allocated into 2 groups: intervention or usual care. The intervention group had access to a self-management education program Living Well with COPD, the support of a case manager, and a written action plan with a selfadministered prescription of antibiotics and prednisone. Patients were instructed to start both antibiotics and prednisone in case of exacerbation with a change in 2 or more symptoms (increased dyspnea, increased sputum volume and/or purulent sputum) for at least 24 hr.

Results: One hundred and sixty six patients with COPD presented with one exacerbation or more in the 12-month study period. Exacerbations (608) were confirmed by a change in at least one symptom; 429 $(70.6 \%)$ by a change in 2 or more. Antibiotics were used in $61.3 \%$ of the exacerbations and prednisone in $47.7 \%$. The combination of antibiotics and prednisone was used more often by the intervention group in exacerbations presenting changes in 2 or more symptoms $(52.97 \%$ vs. $34.8 \%, P<0.001)$. This difference was driven by a higher use of prednisone in the intervention group $(55.7 \%$ vs. $44.3 \%, P<0.001)$ consistent with dyspnea deterioration. In the intervention group, exacerbations treated with antibiotics and prednisone had less risk of requiring an hospitalization than those occurring in the control group (16.5\% vs. $35.1 \%$, $P<0.001)$.

Conclusions: Improved access to treat exacerbations provided by the written action plan plays an important role in reducing hospitalization risk.

\section{BNP after Cardiac Surgery in Patients with Nor- mal Ventricular Function}

Venturini Elio, Antonella Leoni, Dept. of Clinical

Chemistry Civic Hospital Livorno, Italy

Claudio Marabotti, Alessandro Scalzini , Roberto

Testa, Dept. of Cardiology Civic Hospital Cecina, Italy

Background: Brain natriuretic peptide (BNP) is proven marker for diagnosis and stratification of patients $(\mathrm{P})$ with heart failure; furthermore it can be useful for differential diagnosis of dyspnea, for detec- tion of diastolic dysfunction and as guide and monitoring of therapy. Acute coronary syndrome, atrial fibrillation (AF), aortic stenosis and hypertrophic cardiomyopathy are other conditions in which the BNP can be raised. Little is know about the level of BNP in $\mathrm{P}$ undergone cardiac surgery. Aim of the study was to detect the concentration of BNP immediately after $\mathrm{CABG}$ and to follow the course during cardiac rehabilitation (CR).

Methods: we studied $18 \mathrm{P}$ (mean age $67.8 \pm 11.2 \mathrm{yrs}$ ) $9.1 \pm 3.6$ days after surgery and we repeated the evaluation after our program of $\mathrm{CR}$, in average 56 days of distance from $\mathrm{CABG}$. In each $\mathrm{P}$ was performed an echocardiogram (inclusive study of right ventricle, diastolic function and DTI), a determination of BNP (NT-proBNP) and also the six-minute walking test (SMWT). Every effort was made for not varying the therapy during the period of observation. Exclusion criteria were: $\mathrm{MI}$ in the last 3 months, heart and renal failure, use of inotropics drugs and AF after cardiac surgery.

Results: the concentration of BNP was high in both determinations even if it lowered in the second $\left(\mathrm{BNP}_{1}\right.$ vsBNP $_{2}: \mathrm{pg} / \mathrm{ml} 1225.1 \pm 873.2$ vs $\left.708.7 \pm 741 \mathrm{p}<0.001\right)$; also the left atrial volume decreased ( $\mathrm{ml} 50.7 \pm 11.6 \mathrm{vs}$ $46.4 \pm 8.8 \mathrm{p}<0.01) \quad$ while the ejection fraction didn't vary, $\left(\mathrm{EF}_{1}\right.$ vs $\mathrm{EF}_{2}$ : $57.2 \pm 6.7$ vs $\left.59.8 \pm 9.1 \mathrm{~ns}\right)$. There was an increase of the distance crossed to the SMWT ( mt 254.7 \pm 65.4 vs $435.3 \pm 69.6 \mathrm{p}<0.001$ ); glycaemia and creatinine values were normal in both determinations while the hemoglobin increased $(11.5 \pm 1.2$ vs $13.2 \pm 1.3 \mathrm{p}<0.01)$. Other echo parameters(E/A, E/Em, TAPSE, PAPs ) were not meaningfully varied with the exception of DT $(221.6 \pm 66.3$ vs $253.8 \pm 72.3 \mathrm{p}<0.05)$. We have not found correlations between $\ddot{A}$ BNP and: $\ddot{A}$ LAV, Ä SMWT, Ä E/A or Ä E/Em. Instead, the relationship was statistically significant with the DT (r: $0.78 \mathrm{p}<0.01$ ). Also the second determination of the BNP had the followings relationships:

\begin{tabular}{|c|c|c|}
\hline $2^{\text {nd }} B N P$ & $r$ & $p$ \\
\hline$E / A_{2}$ & 0.68 & $<0.01$ \\
\hline$E / E_{2}$ & 0.58 & $<0.05$ \\
\hline $\mathrm{PAPs}_{2}$ & 0.59 & $<0.05$ \\
\hline $\mathrm{EF}_{2}$ & 0.63 & $<0.05$ \\
\hline
\end{tabular}


Conclusion: after $\mathrm{CABG}$, the level of BNP is elevated also in $\mathrm{P}$ with normal ventricular function; the most elevated values were in the immediate proximity of surgery for then being reduced during CR program. The improvement of the diastolic function, pointed out by the increase of the DT, it seems to correlate with the reduction of natriuretic peptides; the relationship of the other indexes of diastolic function, of the EF and of the PAPs with the BNP is detectable only at the second collecting. Is possible to infer that conditions in narrow relationship with the surgery (extracorporeal circulation, quick variations of circulating volume, direct stimulation of the myocardium and impaired lung function due to sternotomy) can induce the liberation of the BNP; this can conceal the association between the incretion of BNP and the indexes of ventricular function.

\section{Improvement in Quadriceps Muscle Strength and Functional Capacities after a 3-Month Home- Based Endurance Training in Lung Transplant Recipients}

Vivodtzev Isabelle, Laboratoire EFCR, CHU de Grenoble \& HP2, Inserm ERI 0017, Université Joseph Fourier, France

Christophe Pison, DMAS. CHU de Grenoble \& LBFA U Inserm 221, Université Joseph Fourier, France

Paulette Mezin, Elisabeth Maclet ${ }^{3}$,

Karen Guerrero, LBFA U Inserm 221, Université Joseph Fourier, France

Jean-Christian Borel, Patrick Levy, Laboratoire EFCR, CHU de Grenoble \& HP2, Inserm ERI 0017, Université Joseph Fourier, France Bernard Wuyam, Laboratoire EFCR, Laboratoire REX-S, Université Joseph Fourier, France

Background: Peripheral muscle dysfunction and reduced exercise capacity are well recognized in lung transplant recipients (LTR) in spite of improved lung function. However, the effect of exercise training in this specific population is still poor studied. We investigated the benefits of training on muscle function and cardio-ventilatory response during exercise in LTR.
Methods: Twelve patients after lung transplantation $\left(\mathrm{FEV}_{1}: 74 \pm 24 \%\right.$ of predicted value) and 12 healthy subjects $(\mathrm{C})$ were studied before and after a 3-month home-based endurance training. Quadriceps strength and fatigability were assessed by maximal twitch tension (TwQ) using magnetic stimulation of the femoral nerve and fiber diameters were obtained after biopsy of the vastus lateralis. Cardio-ventilatory responses were measured during both maximal and constant workload (W) cycle exercise and quality of life was assessed by the Chronic Respiratory Questionnaire.

Results: At baseline, LTR had lower percentage of type I fibers, TwQ, Wmax, $\mathrm{VO}_{2} \max$, VEmax and endurance time than $\mathrm{C}(<50 \%$ of $\mathrm{C}$ each). After training, significant improvement in TwQ $(+44 \pm 26 \mathrm{~N})$, Wmax $(+13 \pm 19 \mathrm{~W})$, endurance time $(+11.5 \pm 11.1$ min) and dyspnea score (CRQdyspnea: $+3.1 \pm 4.4$ points) were observed in LTR ( $p<0.05)$. Furthermore, VE was reduced at submaximal (VE at ventilatory threshold: $-4.5 \pm 6.8 \mathrm{~L} / \mathrm{min})$ and constant $(65 \%$ Wmax $)$ exercise $(-6.4 \pm 5.2 \mathrm{~L} / \mathrm{min})(P<0.05)$. Decrease in exercise-induced fatigability correlated with decrease in VE at initial maximal workload in LTR ( $\mathrm{r}$ $=0.72, P=0.06)$ and in LTR $+\mathrm{C}(\mathrm{r}=0.56, P=0.02)$ and increase in TwQ correlated to increase in CRQdyspnea in LTR ( $\mathrm{r}=0.74, P=0.04)$.

Conclusion: Gains in exercise capacity and in quadriceps strength were observed after endurance training in LTR. The latter may have been involved in improving exercise ventilatory response and dyspnea, supporting the benefit of peripheral muscle strength improvement in exercise tolerance in LTR and even the larger field of chronic respiratory diseases. 